\title{
ANÁLISE DA DEGRADAÇÃO AMBIENTAL NO ALTO CURSO DA BACIA HIDROGRÁFICA DO RIO PARAÍBA
}

\author{
ANALYSIS OF ENVIRONMENTAL DEGRADATION IN THE COURSE \\ OF HIGH RIVER BASIN PARAÍBA
}

\author{
ANÁLISIS DE LA DEGRADACIÓN DEL MEDIO AMBIENTE \\ EN EL CURSO DE ALTA CUENCA PARAÍBA
}

Maria Betânia Rodrigues Silva - Universidade Federal de Campina Grande - Campina Grande - Paraíba - Brasil betaniars@hotmail.com

Pedro Vieira de Azevedo - Universidade Federal de Campina Grande - Campina Grande - Paraíba - Brasil pvieira@dca.ufcg.edu.br

Telma Lucia Bezerra Alves - Universidade Federal de Campina Grande - Campina Grande - Paraíba - Brasil telmalu@yahoo.com.br

\section{Resumo}

A região semiárida do Nordeste do Brasil possui recursos hídricos superficiais escassos e mal distribuídos em nível espacial. Este trabalho tem como objetivo avaliar a degradação ambiental em alguns pontos aleatórios (açudes e leito do rio) na bacia do alto curso do Rio Paraíba. Foram realizados registros fotográficos e coletadas coordenadas geográficas nos pontos aleatórios, identificando as áreas e causas da degradação ambiental na região. Os resultados mostraram que as águas do rio estão recebendo uma elevada carga orgânica, em razão, especialmente, dos efluentes domésticos, dos resíduos sólidos e das práticas agropecuárias; além disso, há outros meios poluentes e degradantes nos mananciais e cursos d'água, como o desmatamento da vegetação nativa e os processos erosivos que agravam os prejuízos ambientais. Em relação aos parâmetros físico-químicos da água, observou-se que os sólidos totais dissolvidos estão adequados para os diversos fins de usos. Houve variação na demanda química de oxigênio, visto que, em todos os pontos amostrados, na maioria das avaliações, a água apresenta demanda química de oxigênio acima do limite permitido pela resolução do Conama $357 / 2005$, bem como as concentrações de fósforos.

Palavras chave: erosão, resíduos sólidos, desmatamento, efluentes domésticos.

\section{Abstract}

The semiarid region of northeastern Brazil has surface water resources scarce and unevenly distributed in space level. This study aimed to assess the environmental degradation in some random points (dams and river bed) in the upper course of the river Paraíba basin. Photographic records were made and collected geographic coordinates in random spots, identifying the areas and causes of environmental degradation in the region. The results showed that the river waters are getting a high organic load, mainly due to domestic effluents, solid waste and agricultural practices contribute to other factors and degrading pollutants to watersheds and watercourses, as well as the clearing of vegetation native and erosion exacerbate environmental damage. In relation to the physico- chemical parameters of the water, it was observed that the total dissolved solids are suitable for various purposes of uses. There was variation in the chemical oxygen demand, noting that in all the sampled points, most of the reviews, the water possesses chemical oxygen demand above the limit allowed by CONAMA Resolution 357/2005, as well as the concentrations of matches.

Key words: erosion, solid waste, deforestation, domestic effluents. 


\section{Resumen}

La región semiárida del noreste de Brasil cuenta con los recursos hídricos superficiales escasos e irregularmente distribuidos en el nivel de espacio. Este estudio tuvo como objetivo evaluar la degradación del medio ambiente en algunos puntos al azar (presas y lecho del río) en el curso superior de la cuenca del río Paraíba. Registros fotográficos se hicieron y se recogen las coordenadas geográficas en lugares al azar, la identificación de las áreas y las causas de la degradación ambiental en la región. Los resultados mostraron que las aguas del río están recibiendo una alta carga orgánica, principalmente debido a los efluentes domésticos, los residuos sólidos y las prácticas agrícolas contribuyen a otros factores y contaminantes degradantes a las cuencas hidrográficas y los cursos de agua, así como la eliminación de la vegetación nativa y la erosión exacerban el daño ambiental. En relación con los parámetros físico- químicos del agua, se observó que los sólidos disueltos totales son adecuados para diversos fines de usos. Hubo variación en la demanda química de oxígeno, y señaló que en todos los puntos muestreados, la mayor parte de las críticas, el agua posee la demanda química de oxígeno por encima del límite permitido por la Resolución CONAMA 357/2005, así como las concentraciones de los partidos.

Palabras clave: erosión, los residuos sólidos, la deforestación, los efluentes.

\section{Introdução}

A água é o recurso natural mais vital para o ser humano e extremamente reduzido. O suprimento de água doce de boa qualidade é essencial para o desenvolvimento econômico, para a qualidade de vida das populações humanas e para a sustentabilidade dos ciclos no planeta. No contexto global atual de baixa disponibilidade de água, ainda existem as disparidades regionais, como no caso do Brasil: a Região Norte apresenta grande oferta desse recurso e baixa concentração populacional; já o Nordeste apresenta uma maior concentração de pessoas e possui restrições hídricas.

A região semiárida do Nordeste do Brasil, com cerca de um milhão de quilômetros quadrados, possui recursos hídricos superficiais escassos e mal distribuídos espacial e temporalmente, o que, em junção com a irregularidade das precipitações, tem provocado períodos dramáticos de seca para a população nordestina. Aliado a esse condicionante climático, o uso indiscriminado dos escassos recursos hídricos vem contribuindo de forma intensa para a degradação da qualidade da água e ampliando os problemas ambientais da região.

Os impactos ambientais são decorrentes da poluição e degradação ambiental, causada em grande parte pelas ações humanas sobre o ambiente, e correspondem às alterações das propriedades físicas, químicas ou biológicas dos elementos naturais; isso implica ainda prejuízos à saúde do homem e aos recursos naturais renováveis. Por isso, não só a identificação dos principais impactos ambientais é importante, mas, sobretudo, são necessárias medidas mitigadoras passíveis de serem aplicadas na área (Alves; Lima; Farias, 2012, p.161). 
No semiárido brasileiro, as condicionantes climáticas podem acentuar ainda mais os efeitos da degradação ambiental, impactando negativamente o solo, a vegetação, os recursos hídricos, a fauna, dentre outros. A degradação ambiental intensa pode transformar ambientes produtivos em ambientes estéreis e inóspitos, e precisa ser controlada através de políticas públicas ambientais adequadas.

Pela observação da paisagem do semiárido nordestino, constatam-se uma gradativa e continuada degradação das condições ambientais. O desmatamento indiscriminado e a erosão, provocados pela ação humana sobre os ecossistemas, contribuem para um processo de desertificação, um problema que tem sido considerado por parcela significativa da comunidade científica.

A bacia hidrográfica, unidade básica das atividades, é entendida como uma área fisiográfica drenada por um curso d'água ou por um sistema de cursos d'água conectados e que convergem, direta ou indiretamente, para um leito ou para um espelho d'água, constituindo uma unidade ideal para o planejamento integrado do manejo dos recursos naturais no meio ambiente por ela definido (Bertoni; Lombardi Neto, 2010, p.334). A região do alto curso do Rio Paraíba apresenta certo grau de degradação ambiental, em decorrência, sobretudo, da utilização do solo, do desmatamento da cobertura vegetal, da contaminação dos recursos hídricos e das queimadas.

Autores como Moura (2006), Souza; Suertegaray; Lima (2010), Alves; Lima; Farias (2012), Maracajá (2007) e Araújo (2010) têm analisado as causas e consequências da degradação ambiental em algumas localidades do alto curso do Rio Paraíba. No entanto, faz-se necessária uma investigação mais detalhada de tais aspectos em toda a bacia desse rio, seguindo as suas regionalizações, com início pelo alto curso até a sua foz.

O Projeto de Integração do Rio São Francisco com Bacias Hidrográficas do Nordeste Setentrional - um empreendimento do Governo Federal sob a responsabilidade do Ministério da Integração Nacional - é destinado a assegurar oferta de água, em 2025, a cerca de 12 milhões de habitantes de 390 municípios do Agreste e do Sertão dos estados de Pernambuco, Ceará, Paraíba e Rio Grande do Norte. A integração do Rio São Francisco às bacias dos rios temporários do Semiárido será possível com a retirada contínua de água que seguirá para um Eixo Norte e Eixo Leste (Brasil, 2010).

A região do alto curso do Rio Paraíba é muito importante para o estado da Paraíba e, em especial, para a Microrregião do Cariri, posto 
que essa região está incluída no Projeto de Integração do São Francisco. Assim, este estudo tem como objetivo avaliar a degradação ambiental em alguns pontos aleatórios (açudes e leito do Rio Paraíba) na bacia do alto curso desse rio.

Material e métodos

A pesquisa foi realizada na bacia hidrográfica do alto curso do Rio Paraíba localizada na região semiárida paraibana, compreendida entre as latitudes $06^{\circ} 51^{\prime} 31^{\prime \prime}$ e $08^{\circ} 26^{\prime} 21^{\prime \prime} \mathrm{S}$ e as longitudes $34^{\circ} 48^{\prime} 35^{\prime \prime}$ e $37^{\circ} 02^{\prime} 15^{\prime \prime} \mathrm{O}$, localizada na parte sudoeste do Planalto da Borborema e limitando-se ao norte com a sub-bacia do Rio Taperoá, ao sul e a oeste com o estado de Pernambuco e a leste com a região do médio curso do Rio Paraíba, conforme pode ser verificado na Figura 1.

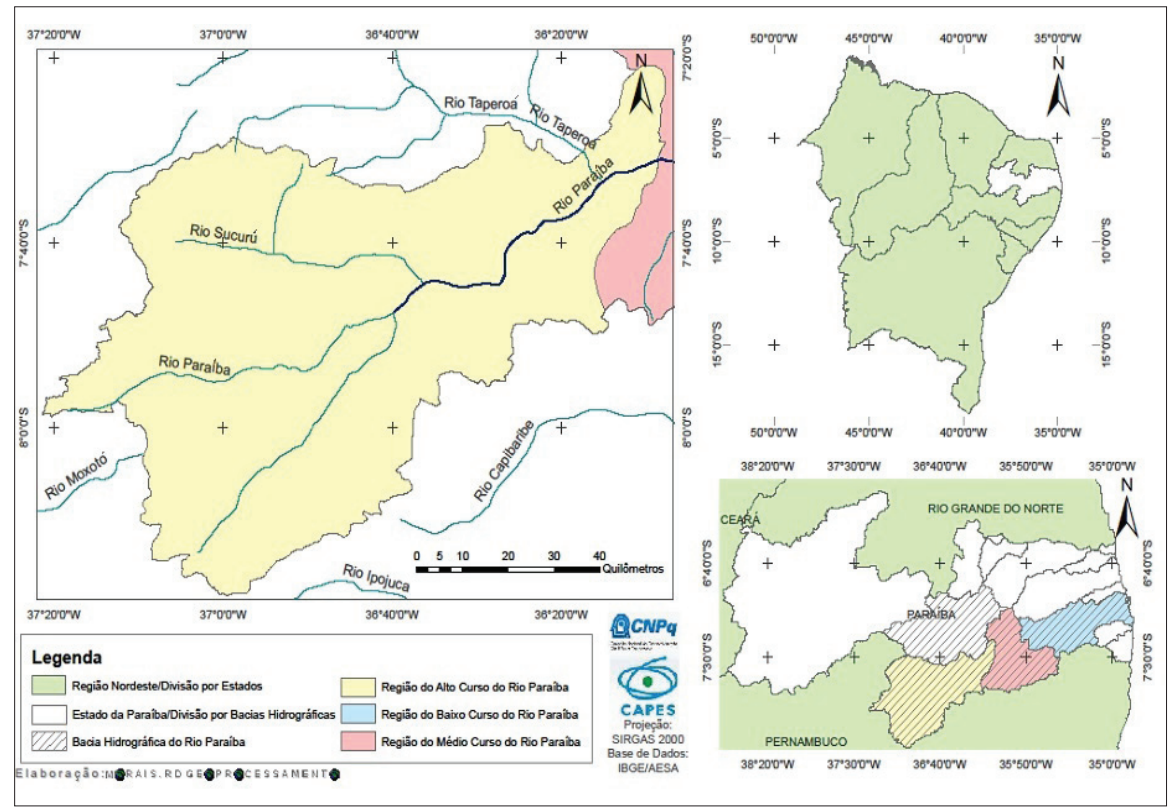

Figura 1: Localização da bacia hidrográfica do alto curso do Rio Paraíba. 
O clima é do tipo BSh, ou seja, semiárido quente, de acordo com a classificação climática de Koppen. O regime pluviométrico na região é caracterizado por precipitações médias anuais que variam entre 350 e 600 $\mathrm{mm}$, com totais anuais concentrados em fevereiro, março, abril e maio (AESA, 2011). O Rio do Meio e o Rio Sucuru são afluentes do alto curso do Rio Paraíba pela margem esquerda, e as contribuições dos rios Monteiro e Umbuzeiro são recebidas pela margem direita. A vegetação predominante é do tipo caatinga hiperxerófila, floresta caducifólia e subcaducifólia. Os solos predominantes são do tipo Luvissolos Crômicos que cobrem todo o cristalino existente na área de abrangência da região do alto curso do Rio Paraíba.

A bacia engloba, total ou parcialmente, a área de 18 municípios paraibanos (Amparo, Barra de São Miguel, Boqueirão, Cabaceiras, Camalaú, Caraúbas, Congo, Coxixola, Monteiro, Ouro Velho, Prata, São Domingos do Cariri, São João do Cariri, São João do Tigre, São Sebastião do Umbuzeiro, Serra Branca, Sumé e Zabelê), distribuídos entre as microrregiões do Cariri Ocidental e Oriental do Estado da Paraíba. A pesquisa foi realizada nos municípios de Monteiro, Caraúbas, Camalaú, Congo e São Domingos do Cariri/PB, e foram registrados os principais pontos de degradação ambiental.

\section{Procedimentos metodológicos}

Através de visitas em campo trimestralmente, no decorrer de 2011 (ano chuvoso) e 2012 (ano seco), foram realizados registros fotográficos in loco para a identificação das áreas degradadas e/ou em processo de degradação. Com o uso de um Global Positioning System (GPS) de precisão, foram registradas as coordenadas geográficas da área dos mananciais e dos pontos selecionados ao acaso situados na calha do Rio Paraíba.

Também foram feitas visitas aos mananciais PA1 (Açude Poções, Município de Monteiro/PB), PA2 (Açude Camalaú, Município de Camalaú/PB), PA3 (Açude Impueira, situado entre os municípios de Camalaú e Congo/PB), PA4 (Açude Cordeiro, Município de Congo/PB), PA5 (Açude Campos, município de Caraúbas/PB) e PA6 (Açude São Domingos, município de São Domingos do Cariri/PB), conforme observa-se no Quadro 1. 
Quadro 1: Localização geográfica dos pontos de coleta de amostras de água nos mananciais e no leito do Rio Paraíba.

\begin{tabular}{|l|c|c|c|c|c|c|c|}
\hline \multirow{2}{*}{ Local de visita } & \multirow{2}{*}{ Nomenclatura } & \multicolumn{3}{|c|}{$\begin{array}{c}\text { Longitude } \\
\text { Oeste }\end{array}$} & \multicolumn{4}{|c|}{ Latitude } \\
\cline { 3 - 8 } & & $\left({ }^{\circ}\right)$ & $\left({ }^{\circ}\right)$ & $\left({ }^{\prime}\right)$ & $\left({ }^{\circ}\right)$ & $\left({ }^{\circ}\right)$ & $\left({ }^{\prime}\right)$ \\
\hline Açude Poções & PA1 & 36 & 59 & 52 & 07 & 53 & 22 \\
\hline Açude Camalaú & PA2 & 36 & 50 & 03 & 07 & 53 & 12 \\
\hline Açude Impueira & PA3 & 36 & 05 & 05 & 07 & 50 & 15 \\
\hline Açude do Congo & PA4 & 36 & 40 & 38 & 07 & 48 & 51 \\
\hline Açude Campos & PA5 & 36 & 32 & 57 & 07 & 45 & 52 \\
\hline Açude São Domingos & PA6 & 36 & 36 & 39 & 07 & 37 & 40 \\
\hline $\begin{array}{l}\text { Ponte do Rio Paraíba, } \\
\text { Monteiro/PB }\end{array}$ & PR1 & 36 & 06 & 26 & 07 & 53 & 14 \\
\hline $\begin{array}{l}\text { Leito do Rio Paraíba } \\
\text { (cidade de Camalaú/PB) }\end{array}$ & PR2 & 36 & 49 & 12 & 07 & 53 & 00 \\
\hline $\begin{array}{l}\text { Ponte (entrada da cidade } \\
\text { do Congo/PB) }\end{array}$ & PR3 & 36 & 50 & 22 & 07 & 42 & 30 \\
\hline $\begin{array}{l}\text { Ponte (Rio Piões), a 5 Km } \\
\text { de Sumé/PB }\end{array}$ & PR4 & 36 & 50 & 00 & 07 & 47 & 14 \\
\hline $\begin{array}{l}\text { Ponte antes da cidade de } \\
\text { Caraúbas/PB }\end{array}$ & PR5 & 36 & 30 & 04 & 07 & 43 & 05 \\
\hline $\begin{array}{l}\text { Sítio Porteira, São } \\
\text { Domingos do Cariri/PB }\end{array}$ & PR6 & 36 & 26 & 47 & 07 & 40 & 02 \\
\hline
\end{tabular}

No leito do Rio Paraíba, os pontos visitados foram PR1 (Ponte do Rio Paraíba, situada no Portal de entrada da cidade de Monteiro/PB), PR2 (Leito do Rio Paraíba, próximo à cidade de Camalaú/PB), PR3 (Ponte localizada na entrada da Cidade do Congo/PB), PR4 (Ponte sobre o Rio Pióes, localizada a $5 \mathrm{~km}$ da cidade de Sumé/PB), PR5 (Ponte localizada antes da cidade de Caraúbas/PB) e PR6 (Sítio Porteira, município de São Domingos do Cariri/PB). Cada ponto de coleta (açudes e leito do Rio Paraíba) foi georreferenciado com o uso de um GPS, registrado com as respectivas coordenadas geográficas (Quadro 1). Já a localização dos pontos visitados (locais onde foram realizados os registros fotográficos) e a delimitação da área do alto curso do Rio Paraíba podem ser verificadas na Figura 2. Além dos registros fotográficos e da determinação das coordenadas geográficas, foi realizada a coleta de amostras de água para a sua posterior análise físico-química e bacteriológica. 


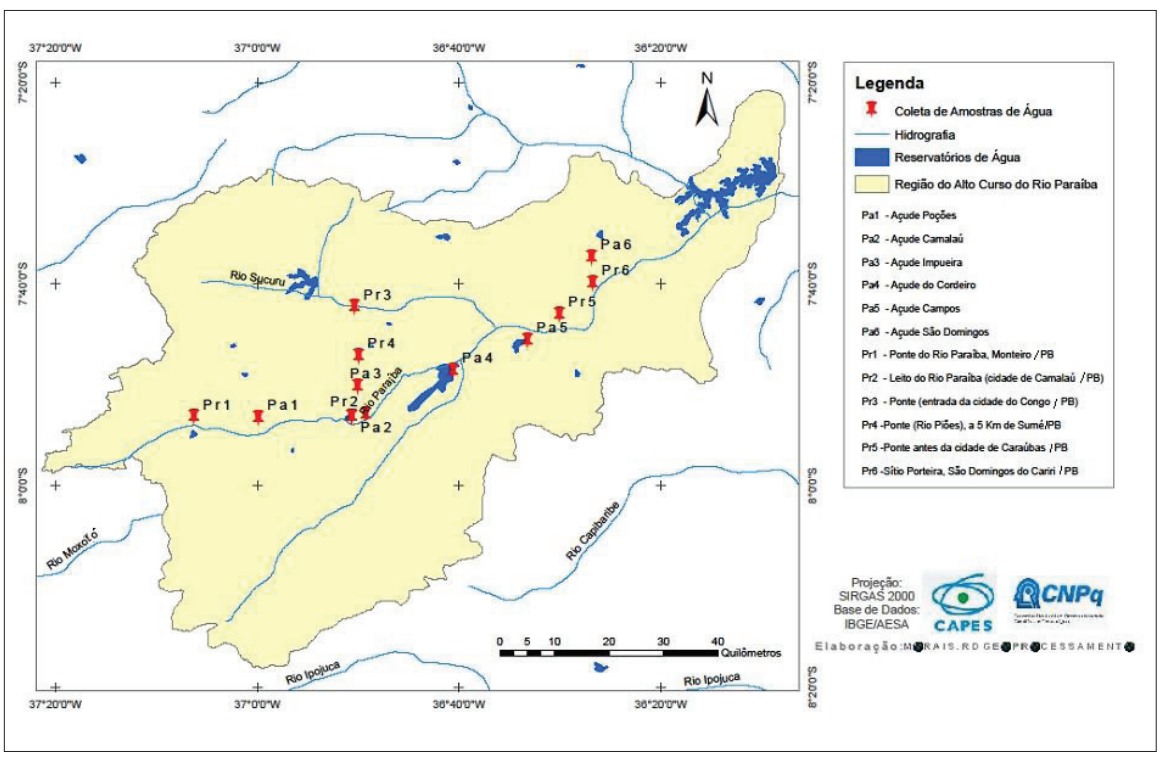

Figura 2: Localização dos pontos visitados, fotografados e delimitação da área do alto curso do Rio Paraíba.

Análise físico-química da água

A avaliação da qualidade da água foi feita através de análise físico-química. As amostras foram coletadas, armazenadas em recipientes plásticos $(500 \mathrm{ml})$ identificados e, em seguida, levadas ao Laboratório do Programa de Saneamento Básico (Prosab). Foram avaliados os parâmetros de Demanda Química de Oxigênio (DQO), Fósforo (P) e Sólidos Totais Suspensos (STD).

\section{Resultados e discussão}

Durante as visitas em campo (trimestralmente), foi possível observar, nas áreas correspondentes aos reservatórios e ao alto curso do Rio Paraíba, alguns agravantes da degradação ambiental, dentre eles: lançamento de efluentes domésticos, disposição de resíduos sólidos, desmatamento da vegetação nativa, erosões, redução das Áreas de Preservação Permanente (APP) e exploração agropecuária. 
Lançamento de efluentes domésticos

A nascente do Rio Paraíba está localizada no município de Monteiro/PB, onde o lançamento de parte dos efluentes domésticos é feita diretamente no leito do rio (Figura 3).

De acordo com o IBGE (2010), o tipo de esgotamento sanitário dos 9.760 domicílios do município é disposto assim: rede geral ou esgoto pluvial (5.401), fossa séptica (231), fossa rudimentar (2.269), vala (359), rio, lago ou mar (8), outro tipo (295) e não tinham esgotamento sanitário (1.197). Observa-se, no entanto, que apesar da maioria dos domicílios da região estar ligada à rede geral de esgoto, ainda há contaminação, pois o despejo do efluente ocorre em locais inadequados e não existe manutenção apropriada das fossas sépticas e rudimentares (Figura 3).
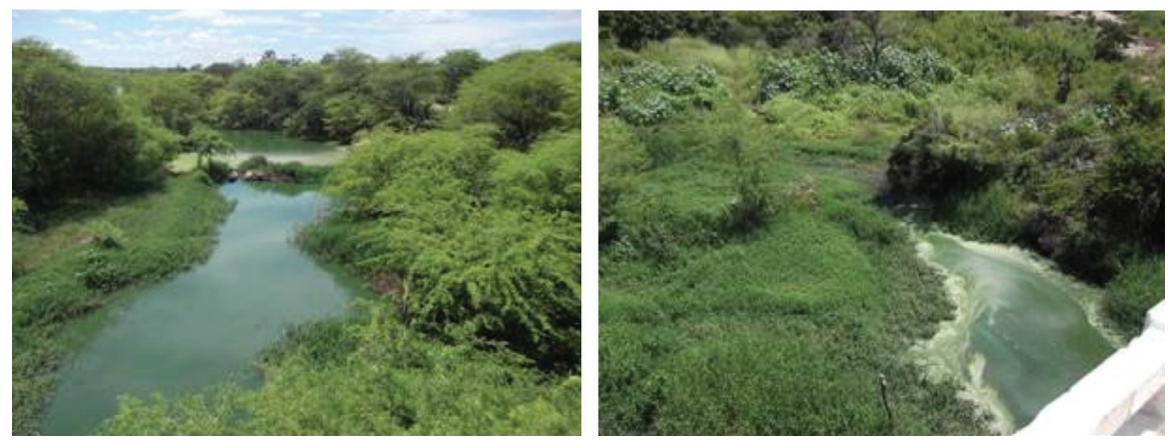

Figura 3: Lançamento de efluentes domésticos no leito do Rio Paraíba, município de Monteiro/PB; março de 2011.

Oliveira e Queiroz (2008) constataram que, no Rio Apodi/RN, a contaminação da água aumenta quando ele se afasta da nascente, em razão da influência das cidades. Assim, é perceptível que esse rio vem sofrendo com a poluição causada pelo despejo de esgotos domésticos, resíduos industriais e lixo urbano. O problema ainda se agrava mais porque nele são lançados, diretamente, os rejeitos líquidos da atividade industrial e efluentes orgânicos domésticos, o que gera altos índices de poluição química no rio, comprovada pela existência, em alta escala, de metais pesados como cádmio, ferro, cromo, chumbo e zinco, lançados no leito do rio por pequenas empresas. Vale ressaltar que a água desse rio é utilizada 
pelos ribeirinhos da seguinte maneira: $2 \%$ deles utilizam-se da água para beber, 3\% para cozinhar, 29\% para o banho e 32\% das pessoas pescam peixes para vender e se alimentar. No Rio Parnaíba, também foi verificada a presença de poluição oriunda do lançamento de esgotos com materiais contaminados (Fadini e Fadini, 2011, p. 11).

Isso causa preocupação, uma vez que a existência de esgoto a céu aberto indica a falta ou a defasagem de saneamento básico, fato que está diretamente ligado a questões de saúde humana, de qualidade de vida e de conservação dos recursos naturais, especialmente da água. A Lei do Saneamento Básico, n. 11.445, de 5 de janeiro de 2007, estabelece diretrizes nacionais para o saneamento básico e institui a Política Federal de Saneamento Básico, que tem como primeiro objetivo a universalização do acesso ao saneamento básico, abrangendo a zona urbana e a rural dos municípios. O saneamento básico é um dos principais indicadores da qualidade de vida e do desenvolvimento econômico e social de uma cidade.

O lançamento de esgoto doméstico caracteriza-se como uma problemática séria, especialmente pelo fato de o Rio Paraíba estar contemplado pelo projeto de transposição das águas do Rio São Francisco (eixo leste). Como o objetivo principal desse projeto é levar água para as regiões mais secas do semiárido, o rio não pode ter a sua qualidade comprometida, ele precisa apresentar as condições gerais de qualidade para o consumo e abastecimento humano, enquadrando-se, portanto, nas classes correspondentes da Resolução Conama n. 357, de 17 de março de 2005, que tem como objetivo a preservação do equilíbrio natural das comunidades aquáticas, de maneira geral.

A poluição reduz, substancialmente, a disponibilidade qualitativa de água para usos como abastecimento doméstico, recreação e preservação dos ecossistemas aquáticos; intensifica doenças de veiculação hídrica, sobretudo nos habitantes ribeirinhos destes corpos d'água; além de causar prejuízos estéticos a eles (Chamun, 2008, p. 22).

\section{Disposição de resíduos sólidos}

Durante as visitas, na bacia hidrográfica do alto curso do Rio Paraíba, foi observada a existência de vários tipos de resíduos sólidos como, por exemplo, papéis, latas, madeiras, garrafas plásticas, vidros, restos de alimentos, utensílios domésticos e roupas, tanto nas margens dos manan- 
ciais como na calha do rio (Figura 4). Essa disposição inadequada de resíduos sólidos no leito do rio e nas margens dos reservatórios ocasiona poluição e degradação ambiental, situação observada no município de Caraúbas/PB (Figura 4A) e Monteiro/PB (Figura 4B).
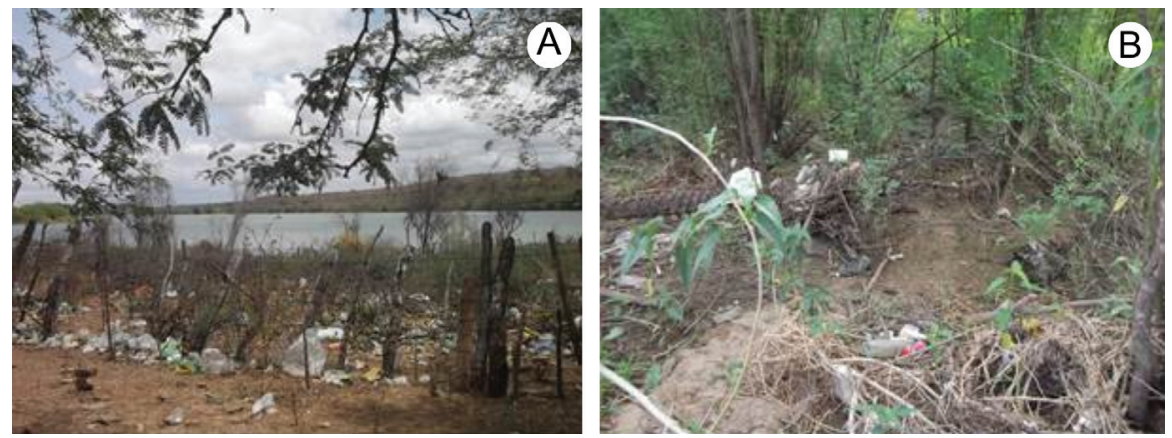

Figura 4: Resíduos sólidos jogados nas margens do Açude Campos, Caraúbas/PB (A), e no leito do Rio Paraíba, Monteiro/PB (B); visitas realizadas em junho e setembro de 2011.

Os resíduos sólidos (domésticos, agrícolas, hospitalares etc.) das cidades encontram-se dispostos a céu aberto. Sob o ponto de vista ambiental, isso pode causar poluição das águas superficiais e subterrâneas, em virtude da percolação do chorume. Em grandes lixões, podem ocorrer a poluição do solo e a atmosférica pela emanação de gases como o metano e o gás sulfídrico, havendo o risco de explosões, visto que o acúmulo desses gases é proveniente da decomposição da matéria orgânica (Pereira, 2009, p. 95).

Em estudos realizados no Rio Parnaíba, foi constatado que o lixo doméstico (restos de comida, latas, garrafas de detergentes e desinfetantes) é um dos problemas ambientais que mais afetam a sua sustentabilidade, pois esse tipo de poluente diminui a quantidade de oxigênio da água e, dessa forma, compromete a qualidade desse recurso utilizado por boa parte da população (Castro, 2008). O problema da má disposição de resíduos se agrava mais ainda no período de chuva, já que as primeiras enxurradas são capazes de arrastar todo o lixo para o rio. No Piauí, os resíduos sólidos domésticos e industriais (inertes, não inertes ou perigosos), inúmeras vezes, são descartados nas sarjetas e lançados nos rios sem nenhum tipo de tratamento, comprometendo a sustentabilidade dos 
lençóis freáticos. Segundo Silva (2008), algumas indústrias teresinenses, além de praticarem o descarte direto desses resíduos nos rios, queimam a céu aberto o lixo de classe considerada perigosa, fato que também contribui para aumentar a poluição atmosférica. Vale lembrar que a Lei n. 12.305, de 2 de agosto de 2010, institui a Política Nacional de Resíduos Sólidos e estimula a criação dos planos municipais de gestão integrada dos resíduos sólidos.

\section{Desmatamento da vegetação nativa}

A exuberância da vegetação nativa na região semiárida é uma consequência da ocorrência da precipitação pluvial, de modo que a alta variabilidade climática identificada condiciona a cobertura vegetal na região. Somada a essa dinâmica natural, a ação antrópica tem ocasionado danos à vegetação nativa (caatinga) da região do alto curso do Rio Paraíba.

O desmatamento na região semiárida vem reduzindo a cobertura vegetal, inclusive, nas APP que margeiam os cursos de água (Figura 5). O uso da vegetação é intenso na região, pois espécies vegetais nativas e exóticas são utilizadas para a construção de cercas e como fontes energéticas. Embora para muitas famílias a lenha seja a única fonte energética disponível, essa prática deve ser combatida, tendo em vista que o desmatamento causa pressão sobre os recursos vegetais ao longo dos anos, especialmente das espécies nativas. Além disso, pequenos produtores rurais utilizam os solos da região para as queimadas e a capinagem. Os agricultores preparam o solo para a agricultura de sequeiro (prática desenvolvida nas margens de açudes e rios, sem o uso de irrigação permanente), de tal forma que agridem o solo e a vegetação nativa.

Valores de 70,6\% e 68\% são relacionados à utilização de lenha no semiárido paraibano, para as microbacias do Riacho do Tronco, Boa Vista/ PB e microbacia do Riacho Namorado, São João do Cariri/PB. É preocupante o fato de que, no semiárido como um todo, a lenha e o carvão não são utilizados apenas para socorrer as necessidades das populações mais pobres, na verdade são usadas em escala comercial para o funcionamento de atividades econômicas, como fornos de padarias, que demandam grande quantidade energética (Melo, 2010, p. 154; Alves, 2012, p. 65). A vegetação natural remanescente e as atividades agrícolas influenciam a qualidade da água de quatro nascentes, com base em períodos de amostragem assim 
como em características do solo e seus diferentes usos (Donadio; Galbiatti; Paula; 2005, p. 119).
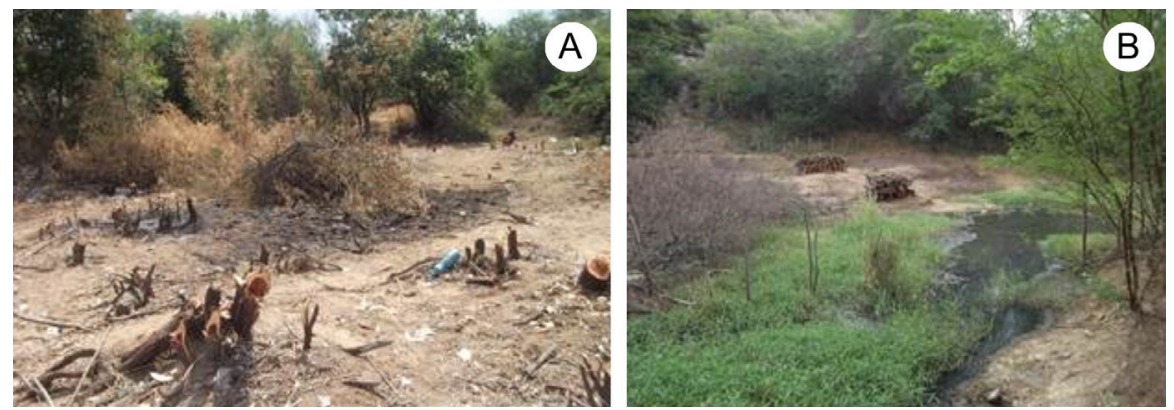

Figura 5: Desmatamento das APP no município de Monteiro/PB (A) e retirada da vegetação nativa para a utilização como fonte energética, Camalaú/PB $(B)$; visitas realizadas em março e dezembro de 2011.

\section{Erosões}

No que concerne às erosões marcantes, foram identificadas na área em estudo espaços abertos (retirada da vegetação) que, invariavelmente no período chuvoso, caracterizado pela variabilidade e torrencialidade, contribuem para os processos erosivos e a desagregação do solo, também provocam o assoreamento dos rios e, consequentemente, dos reservatórios (Figura 6).
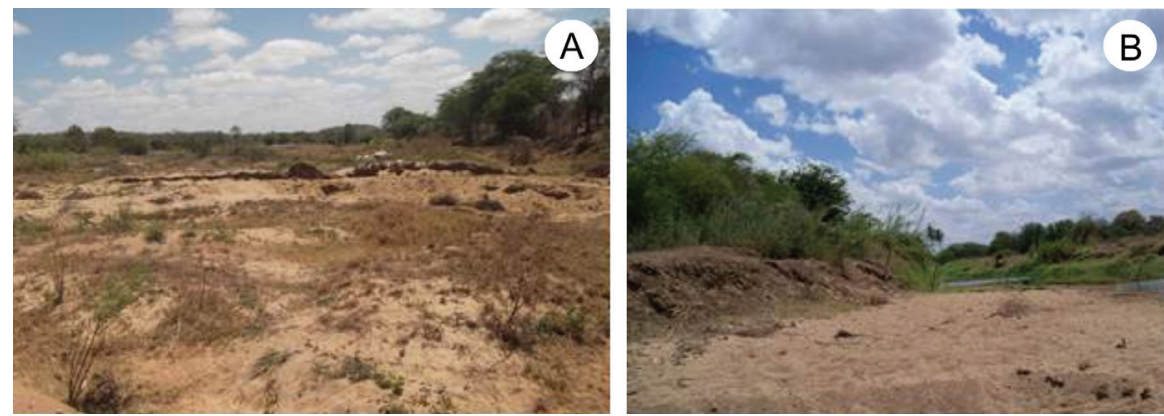

Figura 6: Identificação de assoreamento no curso do Rio Paraíba, no município de Caraúbas/PB (A) e no de São Domingos do Cariri/PB (B); setembro de 2012. 
Além da cobertura vegetal e da torrencialidade ocasionada pela precipitação pluvial, os processos de erosão, transporte e deposição de sedimentos no leito fluvial alternam-se no decorrer do tempo e espacialmente (Guerra; Cunha, 2008, p. 231).

A baixa cobertura de vegetação nativa proporciona o carreamento de grandes quantidades de solo, matéria orgânica e insumos agrícolas para o leito dos cursos d'água no período chuvoso, contribuindo significativamente com o aumento da concentração de sólidos e nutrientes na água dos mananciais (Donadio; Galbiatti; Paula, 2005, p. 119).

\section{Exploração agropecuária}

Na região semiárida do nordeste brasileiro, ocorre de maneira bastante rotineira e intensiva a retirada das espécies nativas da caatinga, para a utilização das áreas desmatadas nas atividades de agricultura e pecuária. Na Figura 7A, podem ser vistas as margens do rio desprotegidas de vegetação, tornando-se propícias ao assoreamento. Na Figura 7B, constata-se que, nas margens do açude Campos, em Caraúbas/PB, como a área é utilizada para a prática da agricultura, há redução da mata ciliar.

Vale destacar que, no Córrego Três Barras, em Marinópolis/SP, ocorreu aumento da concentração dos sólidos na água, nas áreas agricultadas (culturas perenes, culturas perenes irrigadas e culturas anuais), nas áreas habitadas (área urbana e moradias rurais) e nas matas degradadas (Silva et al., 2008, p. 412).
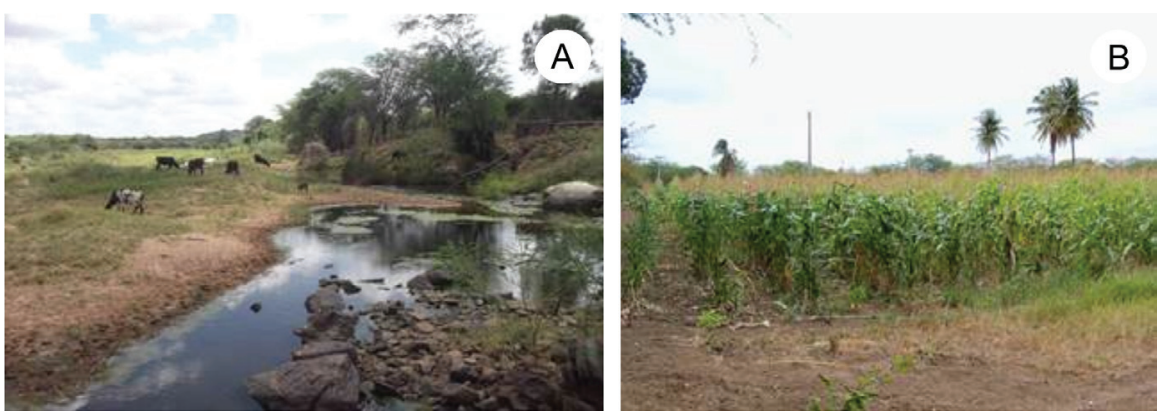

Figura 7: Exploração da pecuária extensiva no leito e nas margens do Rio Paraíba, em Caraúbas/ PB (A), e desmatamento da vegetação nas margens do açude Campos, Caraúbas/PB, para a prática da agricultura (B); março de 2012. 
Elevadas taxas de lotação de rebanhos, especialmente caprinos, em áreas de caatingas, quando associadas a outras formas de pressão sobre a vegetação, causam o empobrecimento e a redução do porte das plantas. Além disso, o pisoteio realizado pelos rebanhos ocasiona a compactação do solo, agravando o processo de degradação (Leal; Vicente; Tabarelli, 2005, p. 696). Esse fato também já foi constatado em outras regiões semiáridas fora do Brasil.

A agricultura, a mais antiga atividade econômica da humanidade, vem sendo acusada de agredir o ambiente por meio da destruição da vegetação, da degradação e poluição dos solos, do lançamento de produtos tóxicos nos mananciais e corpos d'água. Tudo isso é uma séria ameaça à biodiversidade. A erosão dos solos agrícolas é, sem dúvida, um tipo de degradação que causa sérios danos ao meio ambiente; ela é visível e facilmente detectável (Queiroz Neto, 2003, p. 49).

\section{Análise da qualidade da água}

Os resultados dos parâmetros físico-químicos da água coletada nos pontos ao longo do alto curso do Rio Paraíba são apresentados na Tabela 1.

A Demanda Química de Oxigênio (DQO) variou de 34 a 479 mg $\mathrm{O}_{2}$ $\mathrm{L}^{-1}$. Na maioria das avaliações, a DQO da água de todos os pontos encontra-se acima dos limites estabelecidos pela resolução do Conama 357/2005, que fixa valores de DQO até $60 \mathrm{mg} \mathrm{O}_{2} \mathrm{~L}^{-1}$.

De acordo com os dados obtidos, constata-se que a água no leito do Rio Paraíba apresenta concentrações de fósforo variando de 0,10 a 9,53 $\mathrm{mg} \mathrm{L}^{-1}$. Nos pontos de coleta das amostras de água PR1 e PR3, foram constatadas as maiores concentrações de fósforo, possivelmente pela presença de esgosto doméstico e pelo uso de detergentes. Conforme a resolução 357/2005 do Conama, o limite máximo de fósforo contido na água não deve ultrapassar $0,15 \mathrm{mg} \mathrm{L}^{-1}$.

Avaliando a qualidade da água em áreas com diferentes usos do solo, foi verificado que, na nascente com mata, a qualidade da água se mostrou melhor que nas nascentes com uso para fins agrícolas. A cor, dureza, turbidez, condutividade elétrica, alcalinidade, DQO, o pH e Oxigênio Dissolvido (OD) foram as variáveis que mais justificaram essas diferenças. Segundo Primavesi et al. (2002, p. 216), em relação ao teor de fósforo total, foram determinados valores de no máximo $420 \mathrm{mg} \mathrm{L}^{-1}$. 
Tabela 1: Comportamento dos parâmetros físico-químicos da água nos pontos do leito do rio na sub-bacia hidrográfica do alto curso do Rio Paraíba, durante o ano de 2012.

\begin{tabular}{|c|c|c|c|c|c|c|}
\hline \multirow{2}{*}{ Mês/ano } & \multicolumn{6}{|c|}{$\begin{array}{l}\text { Pontos de amostragem da água nos } \\
\text { pontos do leito do Rio Paraíba }\end{array}$} \\
\hline & PR1 & PR2 & PR3 & PR4 & PR5 & PR6 \\
\hline \multicolumn{7}{|c|}{$\mathrm{DQO}\left(\mathrm{mg} \mathrm{O}_{2} \mathrm{~L}^{-1}\right)$} \\
\hline Março/2012 & 200 & 56 & 219 & 56 & 48 & 41 \\
\hline Junho/2012 & 119 & 69 & 88 & 34 & 69 & 77 \\
\hline Setembro/2012 & 418 & 125 & 147 & seco & seco & seco \\
\hline Dezembro/2012 & 479 & 115 & seco & seco & seco & seco \\
\hline \multicolumn{7}{|c|}{ Fósforo (mg L $\left.{ }^{-1}\right)$} \\
\hline Março/2012 & 2,73 & 0,14 & 1,40 & 0,13 & 0,10 & 0,14 \\
\hline Junho/2012 & 7,47 & 0,46 & 4,54 & 1,28 & 0,46 & 0,34 \\
\hline Setembro/2012 & 8,53 & 0,56 & 1,38 & seco & seco & seco \\
\hline Dezembro/2012 & 9,53 & 0,60 & seco & seco & seco & seco \\
\hline \multicolumn{7}{|c|}{ Sólidos totais suspensos $\left(\mathrm{mg} \mathrm{L}^{-1}\right)$} \\
\hline Março/2011 & 65 & 38 & 48 & 17 & 13 & 19 \\
\hline Junho/2011 & 27 & 22 & 16 & 70 & 21 & 16 \\
\hline Setembro/2011 & 80 & 32 & 72 & seco & seco & seco \\
\hline Dezembro/2011 & 90 & 30 & seco & seco & seco & seco \\
\hline
\end{tabular}

A variação de STD ao longo do ano de 2012, com destaque para o PR1, variou de 27 a $90 \mathrm{mg} \mathrm{L}^{-1}$ (Tabela 1). Mesmo assim, conforme os resultados obtidos, pode-se afirmar que a qualidade da água, em relação à concentração de STD, não apresenta restrição para o uso, uma vez que a legislação considera que água com sólidos dissolvidos, em geral, é satisfatória para o uso doméstico e para muitos fins industriais quando apresenta um valor menor que $500 \mathrm{mg} \mathrm{L}^{-1}$. No caso desta pesquisa, em alguns pontos de coleta, existe a presença de esgotos, como já foi anteriormente relatado, sendo necessário o tratamento da água antes de certos usos.

\section{Considerações finais}

De acordo com os resultados observados na pesquisa (2011 e 2012), a bacia hidrográfica da região do alto curso do Rio Paraíba sofre sérios problemas ambientais:

- O Rio Paraíba recebe constantemente cargas orgânicas de efluentes domésticos sem tratamento, contaminando as águas superficiais e também as reservas hídricas subterrâneas; 
- Nas margens dos reservatórios e do Rio Paraíba, há a presença de resíduos sólidos em vários pontos visitados;

- O desmatamento da vegetação nativa, para a utilização como fonte energética, reduzindo as APP, provoca os processos erosivos nas margens e no leito dos rios, visto que isso propicia o transporte dos materiais particulados para os reservatórios, o que diminui a disponibilidade hídrica;

- A exploração agropecuária, caracterizada pelo pastoreio intensivo dos rebanhos e pelas práticas agrícolas tradicionais, também causa danos ambientais.

Em relação aos parâmetros físico-químicos da água, observou-se que os STD estão adequados para os diversos fins de usos. Houve variação na DQO de 34 a $479 \mathrm{mg} \mathrm{O}_{2} \mathrm{~L}^{-1}$, posto que a água apresenta DQO acima do limite permitido pela resolução do Conama 357/2005; e a concentração de fósforo na água variou de 0,10 a $9,53 \mathrm{mg} \mathrm{L}^{-1}$.

Contudo, ressalta-se que a área do alto curso da bacia hidrográfica do Rio Paraíba necessita de planejamento, monitoramento e gestão adequada dos recursos hídricos disponíveis. Ações de atenuação dos causadores da degradação ambiental devem ser adotadas urgentemente, pois esse rio, apesar de ser intermitente, é um importante patrimônio ecológico.

\section{Agradecimentos}

Agradecemos à Coordenação de Aperfeiçoamento de Pessoal de Nível Superior (Capes), pela concessão da bolsa PRODOC e do auxílio à pesquisa, elementos necessários para a realização deste estudo; ao Conselho Nacional de Desenvolvimento Científico e Tecnológico (CNPq), pela concessão de bolsa à terceira autora deste artigo; à Agência Executiva de Gestão das Águas do Estado da Paraíba (AESA/PB), pela concessão de um veículo usado na locomoção da equipe de execução do projeto, para a coleta de dados.

\section{Referências}

AESA. Agência Executiva de Gestão das Águas do Estado da Paraíba. Monitoramento dos volumes dos açudes (Tabelas e Gráficos). 2011. Disponível em: <http:// site2.aesa.pb.gov.br/aesa/jsp/monitoramento/volumes_acudes/indexVolumesAcudes.jsp>. Acesso em: 20 maio 2013.

ALVES, T. L. B.; LIMA, V. L. A.; FARIAS A. A. Impactos ambientais no Rio Paraíba na área do município de Caraúbas/PB: região contemplada pela integração com 
a bacia hidrográfica do Rio São Francisco. Revista Caminhos de Geografia, Uberlândia, v. 13, n. 43, p. 160-173, 2012.

ALVES, T. L. B. Caracterização física e socioambiental da microbacia hidrográfica do Riacho Namorado no município de São João do Cariri/PB. Dissertação (Mestrado em Recursos Naturais) - Universidade Federal de Campina Grande, Campina Grande, 2012.

ARAÚJO, L. E. Climatologia e vulnerabilidade socioeconômica e ambiental da bacia hidrográfica do Rio Paraíba: estudo de caso do açude Epitácio Pessoa (Boqueirão). Tese (Doutorado em Recursos Naturais) - Universidade Federal de Campina Grande, Campina Grande, 2010.

BERTONI, J.; LOMBARDI NETO, F. Conservação do solo. 7. ed. São Paulo: Ícone, 2010. 355p.

BRASIL. Lei n. 11.445, de 5 de janeiro de 2007. Diretrizes Nacionais para o Saneamento Básico. Disponível em: <http://www.planalto.gov.br/ccivil_03/_ato20072010/2007/lei/l11445.htm>. Acesso em: 26 abr. 2011.

BRASIL. Lei n. 12.305, de 2 de agosto de 2012. Política Nacional de Resíduos Sólidos. Disponível em: <http://www.planalto.gov.br/ccivil_03/_Ato2007-2010/2010/ Lei/L12305.htm>. Acesso em: 27 maio 2013.

CASTRO, D. Poluição doméstica. Ag Solve, 2008. Disponível em: < ttp://www. agsolve.com.br/noticia.php?cod=1556>. Acesso em: 10 set. 2013.

CHAMUN, C. C. Avaliação da poluição difusa de esgoto doméstico veiculado à bacia hidrográfica urbana. Dissertação (Mestrado em Engenharia Civil) - Universidade Federal de Santa Maria, Santa Maria, 2008.

CONSELHO NACIONAL DO MEIO AMBIENTE. Resolução Conama 357, de 17 de março de 2005. Disponível em: <http://www.cetesb.sp.gov.br/Agua/praias/res conama_357_05.pdf>. Acesso em: 23 maio 2013.

DONADIO, N. M. M.; GALBIATTI, J. A.; PAULA, R. C. de. Qualidade da água de nascentes com diferentes usos do solo na bacia hidrográfica do Córrego Rico. São Paulo, Brasil. Engenharia Agrícola, Jaboticabal, v.25, n.1, p.115-125, 2005.

FADINI, P. S.; FADINI, A. A. B. Lixo: desafios e compromisso. Cadernos Temáticos de Química Nova na Escola. Edição especial, maio 2011.

GUERRA, A. J. T.; CUNHA, S. B. Geomorfologia: uma atualização de bases e conceitos. 8. ed. Rio de Janeiro: Bertrand Brasil, 2008. 472 p.

GUERRA, A. J. T.; MENDONÇA, J. K. S. Erosão dos solos e a questão ambiental. In: VITTE, A. C.; GUERRA, A. J. T. Reflexões sobre a Geografia Física no Brasil. 2. ed. Rio de Janeiro: Bertrand Brasil, 2007. cap. 2, p. 225-256.

IBGE. Instituto Brasileiro de Geografia e Estatística. Censo Demográfico 2010. Disponível em: <http://www.ibge.gov.br/home/> Acesso em: 15 maio 2013.

JUSTINIANO, E. F. Registro fotográfico. In: VENTURI, L. A. B. (Org.). Praticando geografia: técnicas de campo e laboratório. São Paulo: Oficina de Textos, 2009. 240 p. 
LEAL, I. R.; VICENTE, A.; TABARELLI, M. Herbivoria por caprinos na caatinga da região de Xingó: uma análise preliminar. In: LEAL, I. R.; SILVA, J. M. C. (Eds.). Ecologia e conservação da caatinga. Recife: EDUFPE, 2005. p. 695-715.

MARACAJÁ, N. de F. Vulnerabilidades: a construção social da desertificação no município de São João do Cariri/PB. Dissertação (Mestrado em Geografia) - Universidade Federal da Paraíba, João Pessoa, 2007.

MELO, J. A. B. Diagnóstico físico-conservacionista e das vulnerabilidades como subsídio ao ordenamento territorial da microbacia do Riacho do Tronco, Boa Vista/ $P B$. Tese (Doutorado em Recursos Naturais) - Universidade Federal de Campina Grande, Campina Grande, 2010.

MOURA, G. S. S. de. Geoprocessamento no estudo da desertificação: município de Prata/PB. Dissertação (Mestrado em Engenharia Agrícola) - Universidade Federal de Campina Grande, Campina Grande, 2006.

OLIVEIRA, M. A. de, QUEIROZ, R. A. C. A poluição do Rio Apodi Mossoró/RN e a ação intervencionista do ministério público. IV Encontro Nacional da ANPPAS, 4 a 6 de junho de 2008 Brasília/DF, Brasil.

PEREIRA, R. A. Impactos ambientais decorrentes das condições antroponaturais no município de São João do Cariri/PB. Dissertação (Mestrado em Recursos Naturais) - Universidade Federal de Campina Grande, Campina Grande, 2009.

PRIMAVESI, O.; FREITAS, A. R. DE; PRIMAVESI, A. C.; OLIVEIRA. H. T. Water quality of the canchim's creek watershed in São Carlos, SP, Brazil, occupied by beef and dairy cattle activities. Brazilian Archives of Biology and Technology, v. 45, n. 2, p. 209-217, 2002.

QUEIROZ NETO, J. P. Agricultura brasileira, pesquisa de solos e sustentabilidade. In: RIBEIRO, W. C. (Org.). Patrimônio ambiental brasileiro. São Paulo: Edusp, 2003. p. 46.

SILVA, A. K. M. Resíduos sólidos industriais da cidade de Teresina. Dissertação (Mestrado em Desenvolvimento e Meio Ambiente) - Universidade do Piauí, Teresina, 2008.

SILVA, D. D.; PRUSKI, F. F.; SCHAEFER, C. E. G. R.; AMORIM, R. S. S.; PAIVA, K. W. N. Efeito da cobertura nas perdas de solo em um argissolo vermelho-amarelo utilizando simulador de chuva. Engenharia Agrícola, v. 25, n. 2, p. 409-419, 2008.

SOUZA, B. I.; SUERTEGARAY, D. M. A.; LIMA, E. R. V. Políticas públicas do solo e desertificação nos Cariris Velhos/PB (Brasil). Revista Scripta Nova, v. XIV, n. 311, 2010.

Maria Betânia Rodrigues Silva - Possui Graduação em Engenharia Florestal pela Universidade Federal da Paraíba, Mestrado em Engenharia Agrícola pela mesma universidade e Doutorado em Engenharia Agrícola pela Universidade Federal de Campina Grande. Atualmente faz Estágio Pós-Doutoral em Recursos Naturais na Universidade Federal de Campina Grande. 
Pedro Vieira de Azevedo - Possui Graduação em Agronomia pela Universidade Federal da Paraíba, Mestrado em Meteorologia pelo Instituto Nacional de Pesquisas Espaciais e Doutorado em Bioengenharia - University of Nebraska-Lincoln. Atualmente é professor da Universidade Federal de Campina Grande.

Telma Lucia Bezerra Alves - Possui Graduação em Geografia pela Universidade Estadual da Paraíba e Mestrado em Recursos Naturais pela Universidade Federal de Campina Grande. Atualmente é Doutoranda pela Universidade Federal de Campina Grande.

Recebido para publicação em 27 de setembro de 2013

Aceito para publicação em 15 de dezembro de 2013 